\title{
Research on Transnational Marketing Strategies of New-Style Tea in China -- Based on the Case of Overseas Marketing of Starbucks
}

\author{
Xue Qianru ${ }^{1, a}$, Peng Xinbei ${ }^{2, b}$, Chen Minghua ${ }^{3, c}$ \\ ${ }^{1}$ Department of Economy and Trade, South China Business College Guangdong University of Foreign Studies, \\ Baiyun, Guangzhou, Guangdong, China \\ ${ }^{2}$ Department of Economy and Trade, South China Business College Guangdong University of Foreign Studies, \\ Baiyun, Guangzhou, Guangdong, China \\ ${ }^{3}$ Department of Economy and Trade, South China Business College Guangdong University of Foreign Studies, \\ Baiyun, Guangzhou, Guangdong, China \\ a450241170@qq.com \\ b792576423@qq.com \\ c984854064@qq.com
}

\begin{abstract}
With the upgrading of consumption concept, tea industry in China has entered the era of new-style tea. By analyzing the cases of overseas marketing of Starbucks and combining with the current situation of new-style tea, this paper puts forward some development suggestions for the transnational marketing of new-style tea in China.
\end{abstract}

Keywords: New-style tea, Transnational marketing, Starbucks

\section{我国新式茶饮跨国营销策略的研究一基于星巴克海外 营销案例分析}

薛倩茹 $1, \mathrm{a}$ 彭欣蓓 $2, \mathrm{~b}$ 陈茗桦 $3, \mathrm{c}$

1 广东外语外贸大学南国商学院经贸系, 白云, 广州, 广东, 中国

2 广东外语外贸大学南国商学院经贸系, 白云, 广州, 广东, 中国

3 广东外语外贸大学南国商学院经贸系, 白云, 广州, 广东, 中国

a450241170@qq.com

b792576423@qq.com

984854064@qq.com

摘要

随着消费观念的升级, 中国茶饮行业进入了新式茶饮时代。本文通过分析星巴克海外营销的案例, 结合新式 茶饮发展现状，对我国新式茶饮跨国营销提出可借鉴参考的发展建议。

关键词：新式茶饮，跨国营销，星巴克 


\section{1. 绪论}

\section{1 . 研究的背景}

1. 1. 1. 新式茶饮行业迈入数字化 3.0 时代, 新冠疫情加速行业洗牌升级

近些年来，新茶饮行业成为资本投资的热门，新 品牌蜂拥不断, 行业规模不断扩大。在经过原料迭代 的 1.0 阶段, 品类融合多场景的 2.0 阶段, 2020 年新 式茶饮迈入线上线下数字化的 3.0 阶段。在今年的新 冠肺炎疫情中, 许多茶饮门店被迫停业, 新茶饮行业 遭受巨大冲击, 企业紧急调整策略转为线上外卖服务。 无形中推动了行业升级, 加速行业洗牌, 为头部优质 品牌的扩张带来新一轮契机。

\section{1.2. 新式茶饮需转变格局, 挖掘茶饮蓝海 市场}

目前中国茶饮市场的总规模为 4420 亿元，中国 咖啡市场的总规模为 2155 亿元, 茶饮市场规模仍将 是咖啡市场规模的 2 倍以上, 且与咖啡市场规模差距 将进一步扩大。[1]国内市场新式茶饮品牌众多, 行业 竞争激烈, 产品同质化现象严重, 目前一线城市的新 式茶饮市场已基本饱和。各品牌为了激烈的竞争中脱 颖而出, 积极转变发展格局, 除了细分领域, 转向下 沉市场寻求新的增长点, 还通过跨界融合、跨国营销, 抢占空间巨大的海外市场, 提高品牌市场份额, 寻找 新的发展点。

\section{1.3. 中国新式茶饮未能深耕海外市场, 走 出国门需要经验借鉴}

面对激烈的国内竞争环境以及逐渐饱和的市场, 许多新式茶饮品牌纷纷调整战略布局, 开拓海外新市 场。2018 年, 奈雪的茶、喜茶海外首店陆续在新加坡 开业, 新式茶饮海外版图逐步扩张; 受疫情影响, 新 式茶饮在 2020 年出海受阻, 原本打算扩张的门店大 都无法正常开张。在这种情况下, 奈雪的茶成唯一一 家出海成功的品牌, 在日本大阪开出第一家日本分店。 在扩张过程中, 大部分品牌在产品以及服务的输出方 面仍延续国内的营销策略, 难以融入当地市场, 本土 化程度较低, 需要经验借鉴。

\section{2. 研究的意义}

1.2.1. 借鉴星巴克海外营销经验, 助力新式 茶饮 “扬帆远航”

通过研究星巴克成功的海外营销, 为我国新式茶 饮 “扬帆远航” 提供经验借鉴。本文将从星巴克的品 牌定位、门店选址、形象设计、原料供应、经营模式 等多个维度进行营销策略分析, 并着重研究其本土化
营销的相关举措, 得出星巴克海外经营的经验之谈, 助力新式茶饮借鉴跨国营销策略, 快速抢占品牌认知, 填补海外市场空白, 实现品牌国际化。

\subsection{2. 以新式茶饮为舟, 载中国茶文化出海}

“茶文化” 是独有的中国元素, 是我国新式茶饮 独特的品牌价值。本文将基于传统茶文化, 融合海外 文化，通过多元化的文化交汇，提出我国新式茶饮跨 国营销建议，以新式茶饮为舟，打破文化边界，推动 中国茶文化再次大规模连接海外市场。

\section{2. 新式茶饮的定义及特点}

新式茶饮是指以上等茶叶, 辅以不同萃取方式提 取的浓缩液为原料, 加入新鲜牛奶、奶油或各种新鲜 水果调制而成的饮料。与传统饮品相比, 新式茶饮在 原料选择、生产流程、品牌运营上都做出了升级和创 新, 在产品原料和饮品外观上讲究品质与特色, 在品 牌运营商方面结合线上与线下。 ${ }^{[2]}$

\section{3. 星巴克海外营销案例分析}

\section{1. 适应市场环境, 确立品牌定位}

为了适应海外市场的不同环境, 星巴克对海外不 同门店的概念及职能进行了本土化定位。星巴克选择 中高端的白领阶层或具有一定消费能力的年轻人作 为中国的目标市场, 针对主要消费群体对于休闲、安 静、舒适的独立空间需求, 设定了独立于家庭、工作 室以外的 “第三空间”。

\section{2. 特色形象设计, 迎合地方文化}

在产品包装设计上, 星巴克为了迎合中国传统文 化, 将Vivienne Tam 设计的 Bird and Flora 经典图 案设为蓝本, 巧妙地以水墨画的形式打造了鸟雀、竹 子树、梅花等具有东方特色的图案。在门店设计方面, 星巴克在中国西南及华中区的首家旗舰店位于成都, 其设计融入了成都青陶砖、著名的大慈寺以及四川铜 锅特色等浓厚的蜀地文化元素, 与当地的历史性建筑 融为一体，将中西方文化巧妙地混搭，形成了具有当 地特色的店铺设计, 吸引更多中国市场的消费者去感 受西方咖啡与中国文化的碰撞。

\section{3. 就地取材, 实现产品本土化创新}

跨国公司在一个新市场进行营销, 结合本土的饮 食偏好、传统文化, 实现产品本土化是一个必经的过 程。如星巴克经过品验决定与云南地区的咖啡豆庄园 开展合作，推出一款名为 “凤舞祥云综合咖啡” 新品; 2010 年 3 月, 星巴克将其产品延伸到了茶领域, 推 出了中式茶和异域茶两大类共九款饮品, 成功将茶和 咖啡之间不可逾越的鸿沟联系起来, 将文化障碍转变 为文化融合的创新优势。 


\section{4. 根据消费需求, 制定定价策略}

咖啡文化是以高端的定位引进中国, 因此在大多 数的中国消费者眼中咖啡就是一种 “身份” 和“地位” 的代表。星巴克利用中国消费者心理和行为, 采取了 客户价值定价法, 与世界其他地区相比, 它在中国的 售价要高出 20\%。它对中国的定价策略是 “第三空间 +身份感+咖啡”, 不考虑成本加价率, 只考虑顾客愿 意付多少钱。这一看似高昂的溢价, 顺应了咖啡文化 在中国的影响力, 满足了消费者追求中产阶级身份感 的需求, 提高了咖啡本身的价值。

\section{5. 关注市场热点，及时调整策略}

为了跟上中国快速发展的移动生活趋势和数字 化水平, 以及面对瑞幸这样的本土竞争对手的挑战, 星巴克在 2019 年 5 月开设了 “啡快” 概念店, 推出 线上点餐、到店自取的业务模式; 为应对新冠肺炎疫 情人们生活方式、在家线上办公、减少外出等的改变, 及时调整转变门店停留的消费方式, 使用移动订购和 窗口提货的方式, 推出了 “啡快” 手机点单服务。

\section{4. 新式茶饮现状分析}

\section{1. 国内市场竞争激烈, 头部品牌积极布 局海外市场}

随着消费理念的升级, 围绕 IP 形成茶、咖啡、 酒饮、餐食、文创、环保等的多场景体验店正在发展 成为茶饮的 4.0 阶段。据《2020 新式茶饮消费白皮 书》测算, 新式茶饮市场规模预计到 2020 年底将达 到 1020 亿元。 ${ }^{[1]}$ 随着 “新式茶饮” 的概念在国内消费 者心中扎根, 竞争也在不断加剧, 国内新式茶饮品牌 屡出不穷, 产品同质化严重。

新式茶饮行业进入门槛低, 竞争压力较大, 行业 存活率极低, 发展已从蓝海市场转变为红海市场。除 了稳定在国内的格局, 打破文化边界, 转变品牌战略, 带领中国茶饮文化出海, 实现 “茶饮全球化” 的战略 布局也将成为新式茶饮打造国际化品牌的必然发展 趋势。

\section{2. 海外茶饮市场升温，文化交汇迎新机 遇}

2018 年以来, 作为我国新式茶饮的两大头部品牌 - - 喜茶和奈雪的茶的海外首店陆续在新加坡开业, 新式茶饮海外版图逐步扩张; 受疫情影响, 2020 年新 式茶饮出海受阻, 奈雪的茶成唯一一家出海成功品牌, 2020 年 7 月奈雪的茶在日本大阪开出第一家日本店, 还预计会在美国、韩国开店; 喜茶在新加坡已有 4 个 门店, 并计划 2020 年在东京都内开出第一家日本门 店, 陆续将开出 5 家店; 据喜茶公布的数据, 新加坡 的首家门店开业第一周, 平均日销售 2000-3000 杯。
由此可见, 新式茶饮正逐步走向海外市场, 并获得了 消费者的充分认可。

表 1我国新式茶饮海外门店情况

\begin{tabular}{|c|c|c|c|}
\hline 品牌名称 & 入驻国家 & $\begin{array}{c}\text { 海外首店开 } \\
\text { 业时间 }\end{array}$ & 开店数量 \\
\hline 奈雪の茶 & $\begin{array}{c}\text { 新加坡 } \\
\text { 日本 }\end{array}$ & 2018.12 & 3 \\
\hline 喜茶 & 新加坡 & 2018.11 & 4 \\
\hline 蜜雪冰城 & 越南 & 2018.9 & 60 \\
\hline
\end{tabular}

\section{3. 新式茶饮 “出海” 首战告捷, 仍须汲 取经验}

喜茶进驻新加坡，在保留品牌特色的同时，根据 新加坡当地消费者的口味和市场需求, 与新加坡当地 文化特色创新地融合。如: 推出两款限定的冰淇淋产 品一一榴莲冰淇淋和咸蛋黄冰淇淋; 用最能代表新加 坡的 “新加坡司令” 及 “健力士黑啤” 作为 “醉醉冰 淇淋” 的特色口味; 另外, 喜茶擅用本土化的社交媒 体开展营销, 一方面开通了官方的 Facebook 和 Instagram 账号, 另一方面与当地关注量高的微信公众 号（例如 “新加坡眼”、“新加坡狮城论坛” 等）平台 合作进行营销推广。

新式茶饮在海外不断尝试通过入乡随俗来满足 当地需求, 增加了当地消费者对喜茶的兴趣和好感, 进一步带动了消费, 提升品牌影响力, 但由于仍处在 起步阶段，缺乏系统的本土化营销策略。

\section{5. 新式茶饮跨国营销的发展建议}

\section{1. 依据消费偏好, 组合茶饮搭配}

采用“新茶饮+”搭配组合进行捆绑营销。同时， 组合形式可以根据不同的海外市场特点因地制宜。比 如在日本, 新式茶饮品牌可以根据日本消费者的偏好, 将日本的便当文化与 “新茶饮+烘培” 的组合相结合 推出可乐饼面包、玉子烧面包、饭团面包、鳕鱼面包 等带有日本便当文化的烘培系列, 在茶饮上可以推出 小麦盒装茶或者果茶盒装茶等与便当相配的茶饮产 品。

\section{2. 迎合当地口味, 产品入乡随俗}

新式茶饮产品要想融入当地市场, 与其保持密切 联系是不可或缺的。一方面, 新式茶饮产品的制作原 料可以直接从本土的供应商取货，在减少成本的同时 保证了茶饮的质量。以喜茶为例，新加坡分店在制作 果茶饮品时会采用来自新加坡本土的热带水果, 比如 享有 “果中之王” 美誉的榴莲、黄皮火龙果、释迦等; 
再如喜茶的日本分店会将日本抹茶运用到制作抹茶 奶盖的过程中，很好地贴合了日本消费者的口味需求。

另一方面, 新式茶饮要主动入乡随俗, 积极响应 当地传统节日, 进行特殊的节日营销, 推出特色节日 单品或特调等。例如在西方的经典节日期间 (万圣节 圣诞节) 开展节日主题饮品派对, 限时推出节日菜单 (特饮\&烘培)。

\section{3. 利用场景营销, 延伸门店职能}

新式茶饮品牌可以通过利用线上小程序搭建不 同的兴趣专区, 为志同道合的消费者之间 “汼桥搭线”; 线下构筑社交型门店, 为消费者进行爱好交流提供平 台, 从而达到线上引流线下的目的。例如某个新式茶 饮品牌的日本分店可以在网上搭建一个洛丽塔或动 漫 Cosplay 等个性服装兴趣专区, 并且为相同兴趣标 签的用户提供线上沟通的平台。同时以线下面基提供 茶饮折扣以及座位预定等服务吸引用户转向线下门 店, 提高消费者的转化率。

\section{4. 设计特色周边, 叙述品牌故事}

为了将消费者猎奇心理带来的短期收益转化为 长期的优势, 新式茶饮品牌应积极丰富自己品牌的内 涵, 从产品的特色包装以及周边设计叙述品牌故事。

在产品的包装上, 新式茶饮可以结合当地的传统 文化或潮流文化, 为杯身以及杯盖、杯贴进行独立创 新设计, 便于新式茶饮融入当地的文化群体。比如为 了满足喜爱科幻及计算机题材的消费群体, 可以将赛 博朋克元素渗透到新式茶饮的外包装上。与产品的包 装相比, 产品的周边则更注重对品牌故事的后续讲述, 为消费者传递不同的品牌调性。如: 喜茶可以设计故 宫主题的帆布袋、雨伞等周边产品。

\section{5. 融合当地 IP 文化，打造主题门店}

为了与海外消费者在思想理念上产生共鸣, 新式 茶饮应在保留自身品牌特色的同时, 融合当地热门的 IP 文化, 进行门店主题的本土化设计。以喜茶为例, 门店可以周期性地与某些热门 IP 进行联动, 打造主 题门店, 吸引不同圈层的消费者进行消费。例如日本 的大热动漫 IP 名侦探柯南、哆啦 $\mathrm{A}$ 梦、海贼王等; 将日本居酒屋的产业文化与新式茶饮门头相结合, 使 消费者耳目一新, 进而吸引消费者进店消费。

\section{6. 建设品牌专属社交圈，培养归属感}

为了将体验型消费者转化为常驻的消费群体, 挖 掘潜在消费者, 新式茶饮可通过线上、线下渠道, 在 海外建设自身品牌所属的社交圈, 培养消费者的归属 感、信任感。
线上方面，品牌可借助海外热门的社交平台 (Instagram、Facebook 等)发布产品相关的宣传海报, 产品故事或者理念等, 收集相关的消费反馈, 实现与 消费者的互动 (点赞、评论等)。

线下方面, 可以根据店内装修风格增设相关的合 影陈列, 比如顾客与店员之间、店员内部的合照, 提 升店内温馨感，传递顾客和门店的相互支持和共同进 步的氛围。同时, 店员接待顾客也要符合当地的礼节 礼数, 减少顾客的陌生感。

\section{7. 个性化定制, 提高品牌亲民度}

除了营业门店, 新式茶饮可以在海外开设相关的 茶饮展示概念店, 主打自助体验, 海外顾客可以自带 喜爱的原材料，在指引下制作属于自己的个性茶饮。 在这个过程中顾客可以亲手体验手冲茶, 学到不同茶 叶品类知识, 从而增加顾客对茶文化以及品牌文化的 认知, 提高顾客的活跃度和忠诚度。例如喜茶在新加 坡的茶极客 DIY 店，顾客除了可以体验经典的手冲 茶环节, 还可以参与到不同的主题活动中, 感恩节的 爱心义卖, 环保沙龙等。

\section{6. 结论}

本文分析了新式茶饮行业发展现状, 总结了星巴 克创新、有效的海外营销经验, 并对中国新式茶饮跨 国营销提出了组合产品搭配、产品入乡随俗、场景营 销、融合当地 IP 文化等发展建议, 为中国新式茶饮 开拓海外市场提供了借鉴。

\section{REFERENCES}

[1] CBNData and Nayuki. (2020). White Paper of Newstyle Tea in 2020 https://www.cbndata.com/report/2486/detail?isRea ding $=$ report\&page $=1$.

[2] IiMedia new Economy Industry Research Center. (2020). iiMedia Report| Research and analysis report on the development and consumption trends of new-style tea industry in China in 2020. .https://www.iimedia.cn/c400/71488.html.

[3] Ding, J. (2019) Can new-style tea in China go the way of Starbucks _ Analysis on the marketing strategy of new-style tea. Marketing Management Review. 2019(04):98.

[4] Zhou, H. (2019) Research on the development status and marketing strategy of Starbucks in China. Modern Business. 2019(01):10-11.

[5] Zhang, M. (2019) Analysis of product strategy in cross-cultural promotion -- A case study of Starbucks' Chinese element marketing [J]. Marketing Management Review, 2019(10):74-75. 